\title{
The Dynamics of Productive Assets, Contract Duration and Holdup
}

Renan Goetz ${ }^{\mathrm{a}}$, Yuri Yatsenko ${ }^{\mathrm{b}}$, Natali Hritonenko ${ }^{\mathrm{c}}$, Angels Xabadia ${ }^{\mathrm{a}}$, Awudu Abdulai $^{\text {d }}$

a Department of Economics, University of Girona, Carrer de la Universitat, 10, 17003 Girona, Spain; renan.goetz@udg.edu

correspondence: angels.xabadia@udg.edu, Phone: +34 972-418236, Fax: +34 972-418032

${ }^{\mathrm{b}}$ Dunham College of Business, Houston Baptist University, 7502 Fondren, Houston, TX 77074, USA; yyatsenko@hbu.edu

${ }^{c}$ Department of Mathematics, Prairie View A\&M University, Prairie View, TX 77446, USA; nahritonenko@pvamu.edu

${ }^{\mathrm{d}}$ Department of Food Economics and Consumption Studies, Christian Albrechts University of Kiel, Johanna-Mestorf-Str. 5, 24118 Kiel, Germany; aabdula@,food-econ.uni-kiel.de

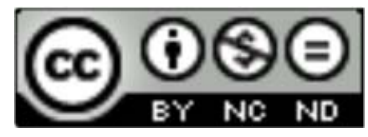

(C) $<2019>$. This manuscript version is made available under the CC-BY-NC-ND 4.0 license http:// creativecommons.org/ licenses/ by-nc-nd/ 4.0/

Based on a work at https://doi.org/10.1016/j.mathsocsci.2018.10.004

Please, cite as: Goetz, Renan-Ulrich; Yatsenko, Yuri; Hritonenko, Natali; Xabadia, Angels; Abdulai, Awudu (2019) "The Dynamics of Productive Assets, Contract Duration and Holdup", Mathematical Social Sciences 97: 24-37 


\title{
The Dynamics of Productive Assets, Contract Duration and Holdup
}

\begin{abstract}
The owner of an asset often transfers the right to use or exploit that asset to an agent in exchange for a rent. A limited time of the license and the failure of the owner's commitment to compensate the agent for any asset improvement are likely to lead to underinvestment (holdup). In this study, we analyze the optimal length a contract would need to have to maximize the owner's income in the short- and long-run. We determine the design of a sequence of renegotiation-proof, overlapping, fixed time contracts that allows eliminating the hold-up problem. The obtained outcomes are tested and illustrated on a specific problem (land lease and soil quality). Numeric simulation demonstrates that the most severe version of the hold-up problem arises when the lease contract is not long enough for farmers to make any investment in the soil quality (less than 3 years on calibrated data).
\end{abstract}

Key words: Contract duration, concession, hold-up problem, output-enhancing investment. JEL Classification: C61, D86, L14, Q15

\section{Highlights}

- We study the optimal duration and renewal of fixed-time contracts if a hold-up problem is present

- The agent's investment and cooperative benefits are intertwined

- We determine the minimum contract length for possible solutions of the hold-up problem

- Overlapping fixed time contracts with advance notice provide a solution of the holdup problem

- We define the optimal length of the contract and advance notice time 


\section{The Dynamics of Productive Assets, Contract Duration and Holdup}

\section{Introduction}

Firms must decide which transactions will take place within the firm itself and which they will have to rely on the markets for. In other words, firms have to define their boundaries. Nobel prize winner Oliver Williamson (1979) considered transaction costs as a critical element in deciding where to draw the boundary between the firm and the market. A significant problem is that market partners often have to make a relationship-specific investment, which can only be recovered within the relationship. If one partner unilaterally decides to end the relationship, then market transactions may be very costly, since investments become sunk costs that cannot be recovered. As a remedy, one may suggest writing a complete contingent contract that safeguards the interests of both parties. However, as argued by Grossman and Hart (1986), the rationality of economic agents is bounded and, thus, prevents the agents from foreseeing all possible future contingencies. Moreover, certain future states cannot be included in a written contract because they cannot be verified by a third party (for example, intangible benefits such as the originality or trendiness of a product, reputation, friendly customer services, or improvements in human capital). Likewise, the non-investing partner has less incentive to renegotiate or accept any demands when the contract has ended if a third party (court) cannot verify the cooperative investment (Harstad 2012, Segal and Whinston 2012). The risk that the non-investing partner will take advantage of this situation can result in underinvestment by the investing partner and thus lead to the hold-up problem.

The existing literature on the hold-up problem has only considered time in a stylized manner. Normally, agents can invest in the first period and expect benefits in the second period. A standard model of a contract (Bolton and Dewatripont 2005) assumes that each period is of a given and identical length, but its duration is not specified. Moreover, investments are frequently modeled not as a stock, but rather as a flow variable. However, real-world examples, like franchise systems or concessions, show that periods of investments and benefits are interrelated and that the dynamics of the investment behavior and realization of the benefits are more complex than portrayed by the standard model. Given this observation, our point of departure is that the agent's investment behavior depends on the length of the 
period or duration of the contract, particularly if investment is not a one-time event, but rather a continuous process while the contract is in place. Moreover, the benefits of investments are often not immediate and can only be fully recovered over time. As an extension of the existing literature, our study focuses on the dynamic description of optimal investment behavior in order to determine the optimal design of contracts in terms of fixed-time duration and renewal in the presence of a hold-up problem.

There are many real-world examples that underline the importance of fixed-time contracts and stock variables in a production process. Within this context, we find landlords who do not cultivate their land themselves, but rather lease it out to agricultural producers in the form of a fixed rent or sharecropping contract over a fixed time horizon. Such leasing contracts affect about $40 \%$ of all cultivated land in Europe and $60 \%$ in North America (Food and Agricultural Organization 2004). Farmers cultivating the land normally invest in the soil quality as this is important for agricultural productivity and farm output (Abdulai and Goetz, 2014). Another common example is the franchise agreement. The franchiser is the owner of the asset which is often in the form of a brand and its associated reputation. A fixed-time contract authorizes the franchisee to exploit the brand while the contract is in place. The reputation of the brand actively contributes to its sales, while investments by the franchisee, such as training and developing personnel, can help improve the brand's reputation and increase sales. Another example from the private sector is the concept of concessions. The concessionaire usually signs a fixed-time contract that allows them to operate within the premises of the concession grantor. As in the case of the franchisee, the overall reputation of the premises and the concessionaire's investments contribute to the success of the business. Examples include business concessions within sports or cultural venues, concessions to retailers to operate in department stores, or concessions to chefs to run restaurants within hotel premises. Within the public sector, we find private companies that enter into agreements with local, regional or national governments to operate public utilities related to water or energy supply, or to provide transport or sanitation services (Worldbank 2011). A common feature of fixed-time contracts is that they give a company the right to exploit public infrastructure. To maintain and augment its returns, the company needs to invest in the infrastructure, as it forms an essential element in the provision of public services.

The aforementioned examples are all similar in that the owner of an asset offers an agent a fixed-time contract, allowing the agent right to exploit the asset. The asset itself is a building 
element for providing a service or producing goods. The duration of such contracts is generally limited and not open-ended. Investment by the agent improves the asset, while intensive production tends to degrade it. Open-end contracts can be found in industrial collaboration such as joint ventures, strategic alliances, or start-up businesses (Comino et al. 2010, López-Bayón and González-Díaz 2010), while the fixed-time format is common for private and public contracts where an asset is involved. Fixed-time contracts frequently take the form of concessions, operating licenses or franchise agreements (Zylbersztajn and Lazzarini 2005, Brickley et al. 2006). ${ }^{1}$

Our study focuses on the question of how an efficient long-run equilibrium can be achieved through a sequence of time-dependent contracts. These types of contracts often include an automatic renewal clause known as the Evergreen Clause. This allows an agreement to continue for a fixed time if the existing agreement is not renegotiated or properly cancelled with advance notice. Evergreen clauses can be found in both consumer and commercial contracts (Voorhees 2016) and examples of such can be found in the agricultural sector (Goodhue et al. 2003) or forest sector (Townsend and Young 2005) or in health care provision (Prives 2013). If the time-dependent contract does not include an evergreen clause it is either in form of an open-end contract, i.e., no renewal but the duration of the contract is open, or in form of a fixed-time contract.

Guriev and Kvasov (2005) analyzed how the long-run equilibrium can be achieved by comparing fixed-time contracts and open-end contracts. As a result of their modelling approach, they find that fixed-time contracts cannot induce efficient investment and one has to resort to open-end contracts. In contrast, our study shows that under fairly general conditions even a sequence of renegotiation-proof fixed-time contracts can induce efficient investment. Moreover, fixed-time contracts seem to be employed more frequently than openend contracts. If the long-run equilibrium can be achieved while the first contract is in place, then the sequence of identical fixed-time contract is able to replicate the first-best solution. However, if the long-run equilibrium cannot be achieved during this time, then it is optimal to either employ a sequence of non-identical contracts or offer no contract at all.

\footnotetext{
${ }^{1}$ Given that fixed-time contracts are normally assigned through a public procurement process based on the request for tenders or proposals we do not consider the possibilities of relational contracts.
} 


\section{Literature}

To overcome the hold-up problem, a number of solutions has been proposed in the literature, including, among others, the assignment of property rights and changes in the structure of governance to allow for the incentives of the partners involved in a transaction to be aligned (Grossman and Hart 1986, Aghion and Tirole 1997, Frascatore 1997). Alternatively, Aghion et al. (1994) or Wait (2005) suggest a contract design that can guide the ex-post renegotiation process, while Felli and Roberts (2015) and MacLeod and Malcomson (1993) discuss improving market contracts, and Baker et al. (2002) emphasize the value of future relationships (relational contracts). The basic idea behind all these theories is the understanding that, without these proposed safeguards, the hold-up problem will result in the contracting parties underinvesting in specific assets (see Felli and Roberts 2015).

The hold-up problem is mostly examined in the context of a principal-agent model, where an agent makes a take-it-or-leave-it offer, or in the form of a bargaining game, where no ex-ante contract exists and the two partners are on equal terms. The common feature of both approaches is that the agent can only make a one-time investment at a pre-specified date, and exchange or bargain does not occur before all investments have been specified. In practice, however, the timing of the investment, duration of the relationship and sharing rule for the cooperative surplus are often negotiated before investments are completed.

Within the context of a bargaining game, Che and Sákovics (2004) allow for a sequence of investments that ends once the partners decide to share the cooperative surplus. The authors find an asymptotically efficient equilibrium, where investments take place all at once. If the time horizon were not infinite, this equilibrium would not be supported. Likewise Gul (2001) shows that there is an asymptotic efficient equilibrium in a hold-up model without ex-ante contracts. However, the analysis does not consider repeated investment decisions, since the model only allows for investment in the first period. Evans (2008) establishes the existence of an efficient equilibrium in the case of a contract that relies on renegotiation with symmetric information as well as production and trade activities verifiable by a third party.

A different strand of the literature is based on the multi-period principal-agent model. Rey and Salanie (1996) show that, under certain conditions and in the absence of a stock variable, renegotiable short-term contracts can be as efficient as long-term contracts, for instance, when agents have no incentives to renegotiate, and physical and monetary variables can be 
transferred between the time periods. Another explanation of the advantages of long-term contracts is based on the emergence of trust in repeated games (Colombo and Merzoni 2006). In light of the available literature, the present study explores, within the principal-agent framework, the optimal trajectory of an agent's investment behavior while the signed contract is in place. Given this new and realistic setting, we analyze if and when a hold-up problem arises. For this purpose, we determine both the socially and privately optimal solutions and analyze possible ways to eliminate the gap between the two, i.e., to overcome the hold-up problem (Lichtenberg 2007, Jacoby and Mansuri 2008). Our analysis extends the previous research by considering the dynamics of a productive asset in continuous time, where investment and benefit sharing are timewise intertwined, the contract duration is determined endogenously and investments affect cooperative benefits in a cumulative way. We extend the work by Yoder et al. (2008), who determine the optimal contract duration, but do not consider the interdependence production and investment decisions have. By allowing investment only at the beginning of the contract period, Yoder et al. (2008) follow a more static approach and do not analyze contract renewal in the form of a sequence of contracts. Our study also expands the work of Hritonenko et al. (2014), who analyze landlord-tenant relationships in a model with a single production input, and find that the hold-up problem does not emerge for certain ranges of model parameters.

The work that is closest to our study is that of Guriev and Kvasov (2005). Like them we consider time not only as a dimension along which the contractual relationship unfolds, but also as a verifiable variable employed in designing the contract. However, unlike these authors, we take into account the explicit form of the production process and consider investment as a stock variable. As discussed above, the latter element is particularly important when the natural resource or asset is employed to produce goods or services. Our model describes production as a function that depends on an output-enhancing input and the quality of the asset.

\section{Statement of the principal-agent problem}

We assume that the principal ${ }^{2}$ is the owner of an asset and makes a take-it-or-leave-it offer to an agent. Within this setup, the principal receives a rent from the agent. In this respect, the

\footnotetext{
${ }^{2}$ For clarity, we refer to the principal with female pronouns and use male pronouns for the agent.
} 
agent is often considered as a residual claimant of the part of cooperative benefits that are not taken away with the payment of the rent. In the analysis that follows, we state the principalagent problem.

Let us denote the continuous calendar time by $t$ and assume that the contract length $T$ is finite and endogenous. The principal's objective is to maximize the income accrued from the rent payment. The magnitude of the rent is subject to the willingness of the agent to sign the contract and its compatibility with personal incentives. To avoid complications related to end-of-horizon effects, we consider the infinite-horizon optimization framework, assuming that the principal and agent (or heirs) live forever.

The principal's objective is to find the value $T>0$ and the rent $R(t) \in[0, \infty)$, that maximize the discounted revenue (income) $I$ :

$\max I=\sum_{j=0}^{\infty}\left[\int_{T j}^{T(j+1)} e^{-r t} R(t) d t-e^{-r T j} V(T)\right]$.

For each contract renewal $j=0,1, \ldots$, the agent's objective is to determine the productive input $m(t)$ and the productivity enhancing investment $n(t), t \in[T j, T j+T]$, that maximize his discounted profit

$$
I_{j}=\max _{m(t), n(t)} \int_{T j}^{T(j+1)} e^{-r t}\left[B(m(t), s(t))-c_{m} m(t)-c_{n} n(t)-R(t)\right] d t,
$$

for a given rent $R(t)$, subject to the participation constraint

$$
B(m(t), s(t))-c_{m} m(t)-c_{n} n(t)-R(t) \geq u_{0}>0,0 \leq n \leq \bar{n}, m(t) \geq 0, \quad s(t) \geq 0,
$$

where the "asset quality" indicator $s(t)$ satisfies the equation

$$
\dot{s}(t)=-h(m(t), s(t))+g(n(t)), \quad s(0)=s_{0}, \quad s(t) \geq 0, \quad t \in[T j, T(j+1)] .
$$

Then, the principal-agent problem is represented as the two-player non-cooperative dynamic game, in which both players (the principal and agent) behave selfishly and maximize their own individual payoffs (1) and (2). We adopt the open-loop Nash equilibrium as the solution concept for this game. Note that the interaction between the players appears only via the rent, which will essentially be used in the qualitative analysis below.

In the problem (1) - (4), the subscript $j$ indicates the number of times the contract has been renewed, i.e., $j=0$ is the initial contract and $j=1$ is its first renewal, and $r>0$ is the discount rate. The parameters $C_{m}$ and $C_{n}$ are the costs of the input $m$ and the investment $n$ 
respectively, and $s(t)$ is the asset quality with its initial condition $s(0)=s_{0}$. The agent's reservation utility is denoted by $u_{0}$ in the participation constraint (3). The constants $C_{m}, c_{n}, s_{0}, \bar{n}, u_{0}$ and bounded real-valued functions $B, h, g$ are given. The agent's revenue from production $B(m, s)$ increases with the input $m$ and asset quality $s$. The changes in the asset quality over time are described by the equation (4). Deterioration of the asset is captured by the function $h(m, s)$ and is greater for more intensive asset use, i.e., for larger $m$ and $s$. Hence, we assume that $h(m, s), h_{m}>, h_{s} \geq 0 .{ }^{3}$ The agent has option to improve the quality of the asset by the investment $n$, which is described by the function $g(n)$.

The given function $V(T)$ in (1) describes the principal's costs and potential losses related to the frequency of signing a new contract. Naturally, such expenses and potential losses depend on the length $T$ of the contract. We consider that short-term contracts result in frequent incurrence of search and transaction costs ${ }^{4}$ such that the function $V(T)$ decreases in $T$. However, the principal must take into account the tradeoff between commitment and flexibility (Gómez-Ibañez 2003). The longer the principal commits herself (long contract duration), the more circumstances are likely to change over the contract's life. However, with a long-time contract, the principal loses flexibility to adjust the contract to new circumstances. Contingencies in the contract could be included, but identifying all the relevant risks and negotiating appropriate contingencies are time-consuming, costly, and impractical (Gómez-Ibañez 2003). Moreover, such uncertainties may be appraisable in the near future, but over time they are likely to increase and become more complex. Several studies focus on the costs and benefits of long-term contracts. Brickley et al. (2006) show that the length of franchise agreements increases if relationship-specific investments are

\footnotetext{
${ }^{3}$ Here and thereafter, the subscript of a function with respect to a variable denotes the partial derivative of the function with respect to this variable.

${ }^{4}$ Not only the principal, but also the agent incurs search costs. However, the principal makes a take-it-or-leaveit offer, where she considers her search cost. Thus, the principal's search costs are part of her offer, but the agent's search costs do not. The agent's search costs form a part of his reservation utility $u_{0}$, which is considered in the model but not formulated explicitly in order to concentrate on the design of the contract by the principal.
} 
important, but tend to decrease with the need for more flexibility. Similarly, Crocker and Masten (1988) show that natural gas contracts are shorter if flexibility is emphasized. These studies are also in line with Pitchford (1995), who found historical evidence (1895-1927) that short forest tenure by the Victorian government (Australia) led to underinvestment in specific capital for timber management. Following this line of argument, we consider losses in flexibility as costs that increase with the length of the contract, therefore $V(T)$ increases in $T$. To identify specifications of the function $V(T)$, it is important to note that they are not related to the optimal contract length. The longer the principal commits herself, the better aligned the principal's and agent's interests are. Then, from the perspective of the principal, the agent invests more efficiently. The optimal commitment duration is independent of the specification of the function $V(T)$ and is based on the solution of the agent's problem in Section 4.1. This provides the efficient investment solution, when there are no incentives for the agent to hold up investments. Considering search and transaction costs together with the loss of flexibility costs, one can see that the function $V(T)>0$ decreases initially in $T$ and increases later as $T$ gets larger. As a result, we can reasonably assume that the function $V(T)$ is $U$ - shaped with a unique minimum at $T^{\mathrm{min}}$.

Given the framework of a principal-agent contract, where the principal has all the bargaining power, we assume that the agent is not in a position to renegotiate the contract once it has expired. The agent can accept or reject the principal's offer. This strong position of the principal is further reflected in the fact that she can easily find a replacement if the agent rejects the offer. For this reason, the function $V(T)$ does not include any renegotiation costs. The principal and the agent can observe the state of the asset before and after the contract has been signed. However, the state of the asset cannot be verified by a third party (court) and, therefore, it cannot be part of the contract. The principal may renew the contract or not, with or without advance notice. Moreover, in accordance with the Nash equilibrium concept, the principal knows the agent's production function. The contract length $T^{*}$ that maximizes the principal's income $I$ depends on the function $V(T)$ and the solution of the agent's optimal decision.

Based on empirical data, we consider that $r<<1$. To simplify notations we omit the subscript $j$ in (4) and use the notation $s(0)=s_{0}$ not only for the initial value of the first contract, but 
also for the initial values in all consecutive renewals $j$ of the sequence of contracts. The same notational simplification is also applied to the variable $\lambda(0), \lambda(T)$ that will be introduced later. Since the agent does not know whether the contract will be renewed or not, he maximizes his profit over the time horizon of the offered fixed-time contract. Consequently, the hold-up problem may arise and the optimal dynamics of the agent's choices may include a decrease of $m(t), n(t)$ and $s(t)$ near the end $T$ of the contract, which also affects the evolution of the optimal rent $R(t)$.

\section{Efficient investment and the first-best solution}

In this section we analyze the principal's and agent's problems by determining the socially optimal outcome. In this case, the principal and agent maximize their incomes and there is no hold-up problem. For the sake of clarity, we focus on the sustainable dynamics of the optimization problem (1) - (4), assuming that the optimal value of $T$ is the same for all $j$. In other words, we assume that the contract duration $T$ is identical for all contracts in the sequence. The assumption is quite reasonable because of the autonomous nature of the problem (1), which does not depend explicitly on the time $t$. Consequently, we will look for a solution of the problem (1) that follows the same dynamics for all $j$. We start with the analysis of the agent's problem.

\subsection{Analysis of the agent's problem}

In this section, we study the dynamics of the optimization problem outlined in (2) - (4) at $j=0$ for a given function $R$. To allow for a qualitative analysis of optimal trajectories, we choose more specific forms of the functions of the model:

$$
\begin{aligned}
& B(m, s)=Y(m, s)=A m^{\alpha} s, \text { with } 0<\alpha<1, \\
& h(m, s)=\mu Y(m, s), \quad g(n)=g_{0} n, 0<\mu<1,
\end{aligned}
$$

where $Y$ is the output, $\alpha$ describes the nonlinearity (concavity) of a production process, and $\mu$ represents the deterioration of the asset as a result of its use in production. Since the revenue $B$ is measured in financial units, the output $Y$ is equal to earnings produced by the input $m$ (at a given level $s$ of the asset quality). Economically, the production function $Y(m, s)$ should be specified as a nonlinear concave function over the entire range of $s$, for example by $s^{\beta}$. However, the exploitation of the asset is often viable only within a limited 
range of $s$. Given that this range is relatively small, we can assume that $\beta$ is equal to 1 over this range. The parameter $g_{0}$ characterizes the improvement of asset quality by the investment $n$. We are aware that the choice of specific functions $B, h, g$ restricts generality of the results, but, on the other hand, it allows us to obtain deeper analytic results, in particular, to find an approximate analytic solution of the agent's problem (2) - (4).

\section{Structure of the optimal trajectories}

Let $m, n$ be bounded functions on $[0, T]$ then the unknown state variable $s$ in (2) - (6) is almost everywhere differentiable on $[0, T]$. Using (5)-(6) and applying standard optimality conditions (Hritonenko and Yatsenko 2013, Hritonenko et al. 2014) to the agent's problem (2) - (6), we obtain an interior optimal solution of $m$, which satisfies the equality:

$$
m^{1-\alpha}(t)=\alpha A s(t)(1-\mu \lambda(t)) / c_{m} .
$$

where the so-called co-state variable $\lambda$ is determined by the equation (9) below. The optimal control $n(t)$ has a bang-bang structure ${ }^{5}$

$$
n(t)=\left\{\begin{array}{c}
0, g_{0} \lambda(t)-c_{n}<0 \\
{[0, \bar{n}], g_{0} \lambda(t)-c_{n}=0 .} \\
\bar{n}, g_{0} \lambda(t)-c_{n}>0
\end{array}\right.
$$

By (8), the structure of the optimal investment $n$ is also determined by $\lambda$. The co-state variable $\lambda$ indicates the future value (shadow price) of a marginal increase in the asset quality and is determined from the differential equation

$$
\dot{\lambda}(t)=\mu A m^{\alpha}(t) \lambda(t)+r \lambda(t)-A m^{\alpha}(t),
$$

with the transversality condition $\lambda(T)=0$. By (5) and (6), the optimal trajectories $(m, n, s)$ have to comply with the state equation (3) given by

$$
\dot{s}(t)=-\mu A m^{\alpha}(t) s(t)+g_{0} n(t), s(0)=s_{0} .
$$

The future value $\lambda$ is equal to zero once the contract expires, i.e., $\lambda(t)=0$. Therefore, by (8), the optimal investment is zero at the end of the interval $[0, T]$, i.e., $n(T)=0$. More generally,

\footnotetext{
${ }^{5}$ The assumption that the decision problem is linear in $n$ is motivated by the fact that agents have incentives to employ the asset most efficiently and investment costs are relatively small compared to rent. Another reason that also holds for the case of agricultural lease of land illustrated below is that investment costs are relatively small compared to obtained additional benefits so that agents have incentive to invest the maximum amount that is compatible with the use of the asset.
} 
the solution (8) means that the agent does not invest, if the marginal costs of the investment $c_{n}$ are higher than the resulting marginal benefits $g_{0} \lambda$. The marginal benefits are given by the improvement in the asset quality multiplied by the shadow price. Obviously, at $c_{n}<g_{0} \lambda$, it is optimal to make the maximum possible investment $\bar{n}$.

The solutions for $s$ and $\lambda$ to the linear differential equations (9) and (10) for a given $m$ are

$$
\begin{aligned}
& \lambda(t)=\int_{t}^{T} e^{-\int_{t}^{u}\left(r+\mu A m(\xi)^{\alpha}\right) d \xi} A m(u)^{\alpha} d u \\
& s(t)=g_{0} \int_{0}^{t} e^{-\int_{u}^{t} \mu A m(\xi)^{\alpha} d \xi} n(u) d u+s_{0} e^{-\int_{0}^{t} \mu A m(\xi)^{\alpha} d \xi} .
\end{aligned}
$$

With the specifications (5) and (6), the agent's optimization problem (2) - (4), still remain nonlinear and challenging to analyze. However, since we are left just with one nonlinear function, $Y(m, s)$, we can estimate meaningful ranges of parameters, when the dynamics of the agent's problem is nontrivial with non-zero investments.

\section{Observation 1 (maximum value of the shadow price)}

The shadow value of the asset quality, $\lambda(t)$, is always smaller than $1 / \mu$, i.e., $\lambda<1 / \mu$. The optimal input $m(t)$ is always positive. The optimal investment in the asset quality, $n(t)$, is zero if $c_{n}>g_{0} / \mu$. However, it can be positive at some combinations of model parameters.

The proof is provided in Appendix I.

Observation 1 indicates that the upper bound of the shadow price is inversely proportional to the deterioration rate, i.e., the higher the deterioration rate is the lower the upper value of the shadow price will be. This makes sense because a high deterioration rate depreciates the future investment benefits.

In the next section, we determine the efficient investment solution, i.e., a solution where the optimal behavior of the agent is aligned with optimal perspective of the principal. The derived efficient investment solution will be quite significant as a limiting asymptotic case for dynamic trajectories of the optimization problem (2) - (6).

Efficient investment solution and steady-state analysis 
If the agent's contract is of infinite duration $T=\infty$, and the external conditions stay unchanged, the principal's and agent's interests are aligned, which characterizes the efficient investment solution (Bolton and Dewatripont 2005). In this situation, the principal and agent would have common interests, the principal indefinitely commits, and, consequently, the hold-up problem does not arise.

Such sustainable infinite-horizon version of the optimization problem (2) - (6) is stated as

$$
\begin{aligned}
& \max _{m, n} \int_{0}^{\infty} e^{-r t}\left[A m^{\alpha} s-c_{m} m-c_{n} n-R\right] d t \\
& \dot{s}=-\mu A m^{\alpha} s+g_{0} n, m>0, \quad \mathrm{~s}>0,0<n<\bar{n} .
\end{aligned}
$$

To find a sustainable (steady-state) solution to (13), it is enough to disregard the initial condition $s(0)=s_{0}$ in $(10)$. Then, the steady-state sustainable regime $(\hat{m}, \hat{n}, \hat{s}, \hat{\lambda})$ is defined by the equations:

$$
\begin{aligned}
& \hat{m}^{1-\alpha}=\frac{A \alpha(1-\mu \hat{\lambda}) \hat{s}}{c_{m}}, \\
& \hat{n}=\left\{\begin{array}{cc}
0, & g_{0} \hat{\lambda}-c_{n}<0 \\
{[0, \bar{n}],} & g_{0} \hat{\lambda}-c_{n}=0, \\
\bar{n}, & g_{0} \hat{\lambda}-c_{n}>0
\end{array}\right. \\
& \hat{s}=\frac{g_{0} \hat{n}}{\mu A \hat{m}^{\alpha}}, \\
& A \hat{m}^{\alpha}=\frac{r \hat{\lambda}}{1-\mu \hat{\lambda}} .
\end{aligned}
$$

The equations (14) - (17) follow from the equalities (7) - (10), although they can also be derived directly from analysis of the optimization problem (13). By (17), we have

$$
\hat{\lambda}=\frac{A \hat{m}^{\alpha}}{r+\mu A \hat{m}^{\alpha}}<\frac{1}{\mu} .
$$

In (18), the term $\frac{r}{A m^{\alpha}}$ determines the difference between the steady-state shadow price $\hat{\lambda}$ and the upper bound $1 / \mu$ of the shadow price. Hence, if the discount rate is small and/or the input $m$ is very productive, then the steady-state shadow price $\hat{\lambda}$ is close to the maximal value of the shadow price, which is the inverse of the deterioration rate. In other words, the 
steady-state shadow price decreases with an increase in the discount rate and /or with a decrease in the productivity of the input $m$.

It is clear from the nonlinear system (14) - (17) that its positive solution exists only for particular ranges of the model parameters. For example, if $c_{n}>g_{0} / \mu$, then $g_{0} \hat{\lambda}-c_{n}<g_{0} / \mu-c_{n}<0$, the optimal investment $\hat{n}=0$ by (15) and asset quality $\hat{s}=0$ by (16). Obviously, from an economic point of view, only a non-trivial case where $\bar{n}>0$, $\hat{m}>0, \hat{s}>0$, is interesting, and, thus, it makes sense to concentrate on the case $c_{n}<g_{0} / \mu$.

\section{Theorem 1 (on efficient investment regime).}

If $c_{n}>g_{0} / \mu$, then the nonlinear system (14) - (17) has a unique trivial solution $\hat{m}=\hat{n}=\hat{s}=0$. The system (14) - (17) may have a unique positive solution $(\hat{m}, \hat{n}, \hat{s}, \hat{\lambda})$ at some values of model parameters, for example, if $c_{n}<g_{0} / \mu$ and $C=\frac{A \mu}{r}\left(\frac{g_{0} \bar{n} \alpha}{c_{m} \mu}\right)^{\alpha}>>1$.

The proof and an approximate closed-form solution for $(\hat{m}, \hat{n}, \hat{s}, \hat{\lambda})$ at $C \gg 1$ are provided in Appendix II.

We shall notice that the value of $\hat{\lambda}$ is close to $1 / \mu$ under the condition $C>>1$, and therefore, the condition $C_{n}<g_{0} / \mu$ is "almost sufficient" for having the nontrivial dynamics $\hat{n}>0$. The condition $C \gg>1$ holds at certain combinations of parameter values, namely, large enough maximum investment $\bar{n}$, or small enough discount rate $r$, or large enough productivity $A$, or a combination of these conditions.

Thus, the efficient investment solution of the equations (14) - (17) is constant over time. Guriev and Kvasov (2005) also obtain a constant efficient investment solution, but their reasons are quite different. The stationarity of their choice variable, investment, is the result of the chosen modeling approach, where investments are additively separable over time. In contrast, all our efficient variables are constant because our efficient investment solution coincides with the steady-state solution.

\subsection{Analysis of the principal's problem}


The problem of the principal is described by the equations (1) - (6) and consists of finding the optimal value $T>0$ and the function $R(t), t \in[0, \infty)$, that maximizes the principal's net income $I$. Moreover, the principal knows the optimal behavior of the agent, so she can choose $R(t)$ such that the entire cooperative benefits are extracted, and the agent is left only with the minimal possible net income equal to the reservation utility $u_{0}$. Therefore, the optimal $R(t), t \in[0, \infty)$, is a corner solution along the participation constraint. The optimal rent is then given as

$R(t)=A m^{\alpha}(t) s(t)-c_{m} m(t)-c_{n} n(t)-u_{0}, t \in[0, \infty)$.

\section{First-best solution}

As shown in Theorem 1, the agent's problem has a unique constant efficient investment trajectory $(\hat{m}, \hat{n}, \hat{s})$, which is positive if $c_{n}<g_{0} / \mu$ (otherwise, there is no production). Then the optimal sustainable rent $\hat{R}$ over $[T j, T(j+1)]$ is also constant and is the same for all periods $j:$

$\hat{R}=A \hat{m}^{\alpha} \hat{s}-c_{m} \hat{m}-c_{n} \bar{n}-u_{0}$, or

$$
\hat{R}=A^{\frac{1}{1-\alpha}}\left(\frac{\alpha}{c_{m}}\right)^{\frac{\alpha}{1-\alpha}} \hat{s}^{\frac{1}{1-\alpha}}-c_{m} \hat{m}-c_{n} \bar{n}-u_{0},
$$

where $\hat{m}$ and $\hat{s}$ are determined by Theorem 1 . In this case, the total discounted principal's net benefits (1) along the sustainable trajectory $(\hat{m}, \hat{s})$ are

$$
\hat{I}(T)=\hat{R} \sum_{j=0}^{\infty} \int_{T j}^{T(j+1)} e^{-r t} d t-\sum_{j=0}^{\infty} e^{-r T j} V(T)=\hat{R} \int_{0}^{\infty} e^{-r t} d t-\frac{V(T)}{1-e^{-r T}} \cong \frac{\hat{R}}{r}-\frac{V(T)}{1-e^{-r T}}
$$

and the maximum of $\hat{I}(T)$ is attained at the value $T^{\mathrm{min}}$ that delivers the minimum of the function $V(T) /\left(1-e^{-r T}\right)$. Combining the efficient investment solution with the principal's decision problem yields the formulation of the first-best solution.

\section{Observation 2 (the first-best solution and its implementation)}


i) The first-best solution of the original principal-agent problem (1)-(6) is given by $T^{\min }=\operatorname{argmin} V(T) /\left(1-e^{-r T}\right)$, the investment $(\hat{m}, \hat{n}, \hat{s})$ is determined from (14)-(17), $R=\hat{R}$ is given by (21), and $\hat{I}\left(T^{\mathrm{min}}\right)>0$ is given by (22).

ii) If the contract length is the only time-related term in the contract, then the first-best solution cannot be achieved.

Proof: Part i) follows from Theorem 1 and equation (22). Part ii) is derived from the fact that the principal's optimal contract length $T^{\mathrm{min}}$ is finite, so, the agents are not fully incentivized to invest over the full length of the contract. As a result, the agent holds up investments that cannot be fully recovered within the contract. On the other hand, an infinite contract length is not optimal for the principal because of the increase in the costs $V(T)$. Thus, the first-best solution will not be achieved if the contract length is the only constituting time element in the contract. $\square$

\section{Efficient investment and advance notice}

Observation 2 demonstrates that the first-best solution cannot be achieved if the contract is defined only by its length. Our systematic analysis of the dynamics of the agent's investment behavior in Section 4 indicates that another time-related control, namely, the advance notice for renewal or termination of the contract, can fully eliminate the hold-up problem.

The consideration of this additional contract control parameter is supported by real world examples. For instance, concessions are often granted for a long-term period with the possibility of renewal. Gómez-Ibañez (2003) reports that Ferrocarriles Argentinos offered 1980 ten-year concessions for six commuter rail lines with the possibility of a second tenyear renewal. In the U.S., 18 jurisdictions have adopted statutes regulating franchise renewals. The period for providing the advance written notice varies, depending on the jurisdiction and the reason why the franchisor is providing the notice. In some jurisdictions, the franchisor is required to provide a written notice within a certain specified period for all non-renewals, including Arkansas (90 days), California (180 days), Iowa (6 months), and the Virgin Islands (120 days). Similarly, for the rent of agricultural land, the German Civil Law Code ( $\S 585 \mathrm{ff}$ BGB) establishes that the advance notice time is approximately two years (third working day of the year for the end of the coming year). This advance notice time is 
valid for the ordinary notice of termination. In the case when a contract is breached, the extraordinary notice of termination is $3-12$ months.

\subsection{Dynamics of the agent's investment behavior}

The length of the advance notice is directly related to the point of time (switching point) when the agent changes his optimal investment behavior following the formulas (8) - (10). In order to concentrate on economic issues, we assume that a solution exists and focus on the qualitative analysis of its properties for different lengths $T$ of the contract period. Then, the formulas (9) and (10) lead to

$$
\begin{aligned}
\lambda(t) & =\int_{t}^{T} e^{-\int_{t}^{u} r+\mu A m^{\alpha}(\xi) d \xi} A m^{\alpha}(u) d u=\frac{1}{\mu}\left[1-e^{-\int_{t}^{T} r+\mu A m^{\alpha}(\xi) d \xi}\right]-\frac{r}{\mu} \int_{t}^{T} e^{-\int_{t}^{u} r+\mu A m^{\alpha}(\xi) d \xi} d u \\
& =\frac{1}{\mu}-\frac{1}{\mu}\left[e^{-\int_{t}^{T}\left(r+\mu A m^{\alpha}(\xi)\right) d \xi}+r \int_{t}^{T} e^{-\int_{t}^{u}\left(r+\mu A m^{\alpha}(\xi)\right) d \xi} d u\right] . \\
s(t) & =e^{-\mu A \int_{0}^{t} m^{\alpha}(\xi) d \xi}\left[s_{0}+g_{0} \int_{0}^{t} e^{\mu A \int_{0}^{u} m^{\alpha}(\xi) d \xi} n(u) d u\right] .
\end{aligned}
$$

The dynamics of the dual variable $\lambda(t)$ is crucial for revealing the structure of the optimal investment. It is obvious that $\lambda(t)$ decreases from $\lambda(0)>0$ to $\lambda(T)=0$, so, by (8), the investment $n(t)$ is zero at the end of the interval $[0, T]$. To guarantee that the bang-bang investment $n(t)$ has at most one switching point, we prove in Appendix III that $\lambda(t)$ decreases monotonically.

Therefore, from (15), the optimal investment $n(t)$ is bang-bang ${ }^{6}$ and is given by

$$
n(t)=\left\{\begin{array}{l}
\bar{n}, 0 \leq t \leq t^{*} \\
0, t^{*}<t<T
\end{array},\right.
$$

where the unique switching point, $t^{*}>0$, is determined from the equation $\lambda\left(t^{*}\right)=c_{n} / g_{0}$.

\footnotetext{
${ }^{6}$ The linearity of $g(n)$ with respect to the choice variable $n$ is responsible for the bang-bang solution (25). Long et al. (2014) show that the choice variable may not only exhibit a monotonously increasing or decreasing behavior but can also change the sign over time.
} 
Thus, the instant $t^{*}$ depends on $\lambda$, which, in turn, depends on $m$ by (23). The optimal input $m(t)$ is always positive and derived from the equation (14) as

$m^{1-\alpha}(t)=\frac{A \alpha}{c_{m}} s(t)[1-\mu \lambda(t)]$

For the instant $t^{*}, 0 \leq t^{*}<T$, the equation $\lambda\left(t^{*}\right)=c_{n} / g_{0}$ and the formulas (23) - (26) define the solution of the agent's problem.

For the qualitative analysis of the properties of the solution, we start with the case of shortterm contracts.

\subsection{The case of short-term contracts}

Intuitively, there exists a small value of the contract length $T$, that does not provide sufficient incentives for the agent to invest in the asset quality. This value obviously depends on values of other model parameters. In Appendix IV, we obtain the estimate

$$
T<-\frac{\ln \left(1-\mu c_{n} / g_{0}\right)}{r+\mu A\left(A \alpha s_{0} / c_{m}\right)^{\frac{\alpha}{1-\alpha}}} .
$$

The estimate (27) is sufficient in the sense that the investment is always zero on an interval that satisfies (27). Equations (23) - (26) show that short-term or spot contracts in the absence of investment lead to an exponential deterioration of the stock and a decrease in the productive input. This pattern is repeated if the contract is renewed with the same short contract duration. In other words, a sequence of short-term or spot contracts leads to a continuous degradation of the stock. For the design of contracts, the condition (27) is of interest, as it provides guidance for the choice of the optimal contract duration that avoids a situation where agents do not invest at all. If the deterioration rate $\mu$ is high, and/or the productivity $A \hat{m}^{\alpha}$ of the asset is low, it is more likely that the equation (27) holds and the agent does not invest during the period of the contract. Similarly, if the values of the parameters, $\mu c_{n} / g_{0}$, are such that this term is close to 1 , the absolute value of the logarithm is large. Hence, only very long-term contracts may avoid non-investment in the asset quality. However, if the values of the parameters, $\mu c_{n} / g_{0}$, are such that the term is close to 0 , then, even contracts that have short durations may avoid non-investment. Hence, the smaller the 
investment lost through deterioration is, or the larger the increase in asset quality is, the higher the incentive to invest.

\subsection{The case of intermediate term contracts}

Let the contract length $T$ be not too small, such that the condition (27) does not hold. In the general case, we cannot obtain explicit formulas for a solution of the agent's problem. However, economic rationale allows us to narrow down the range of values for some of the parameters of the model. We can also rule out extreme cases, where the degradation rate of the asset is very high or the asset is very productive. Specifically, we focus on typical cases where $\mu A<<1$. Moreover, in line with economic rationale, we have assumed from the beginning that $r<<1$. These two conditions allow us to provide an approximate solution for $\lambda(t)$ and $s(t)$.

As shown in Appendix V, the solution of $\lambda(t)$ to the equation (23) can be approximated by

$$
\lambda(t) \approx \frac{1}{\mu+r / A m^{\alpha}(t)}\left[1-e^{-\left(r+A m^{\alpha}(t)\right)(T-t)}\right] .
$$

The equation (28) describes the dynamics of the shadow price and complies with the transversality condition, $\lambda(T)=0$, as $t$ approaches $T .{ }^{7}$ Using the equation (8), we can show that switching from investment to no investment occurs at time $t^{*}$ when

$$
\frac{c_{n}}{g_{0}}=\lambda\left(t^{*}\right) \approx \frac{1}{\mu+r / A m^{\alpha}\left(t^{*}\right)}\left[1-e^{-\left(r+\mu A m^{\alpha}\left(t^{*}\right)\right)\left(T-t^{*}\right)}\right] \text {, }
$$

where the optimal switching time $t^{*}$ satisfies the approximate formula

$$
t^{*} \approx T+\ln \left(1-\frac{c_{n}}{g_{0}}\left(\mu+r / A m^{\alpha}\left(t^{*}\right)\right)\right) \frac{1}{r+\mu A m^{\alpha}\left(t^{*}\right)} .
$$

The evolution of the investment and the shadow price are depicted in Fig. 1, where $t^{*}$ indicates the optimal switching time. Equations (25) and (30) clarify the structure of the optimal investment given by (8) and clearly indicate the optimal change in the investment regime. However, the equation (30) still involves the unknown value $m\left(t^{*}\right)$. Even knowing that the function $m(t)$ is slowly changing, we do not have any initial condition for it. In the

\footnotetext{
${ }^{7}$ The approximate formula (28) matches the formula (51) for $\lambda$ in Appendix IV, when $r$ is small but $\mu$ is not small.
} 
numerical analysis of Section 6, we provide an illustration of the evolution of $m$ for a specific problem of a nitrate application in agriculture. A more practical estimate for $t^{*}$ is obtained in the next section.

Fig. 1 Evolution of the asset shadow price and the investment over time

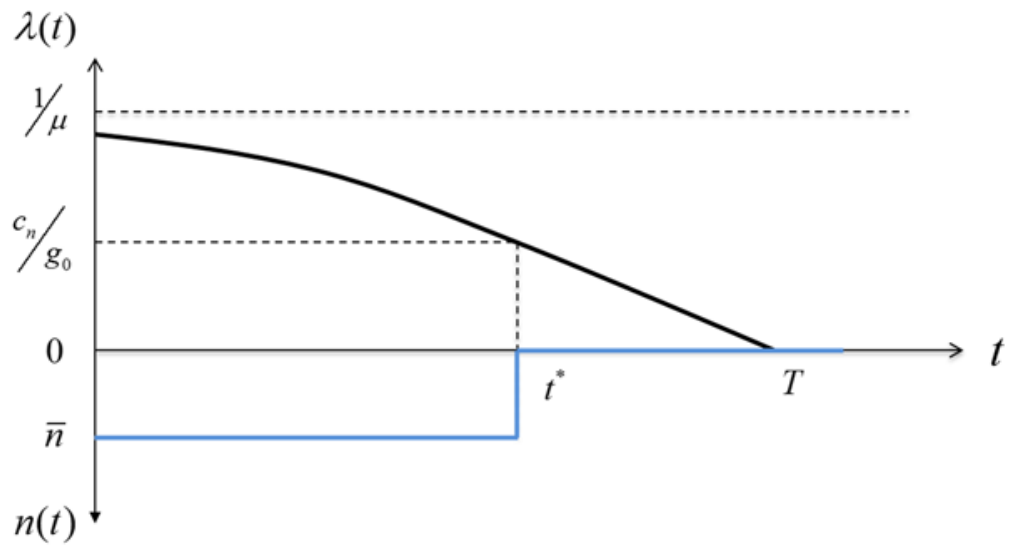

Analogously to (23), the equation (24) can be solved under the assumption $\mu A<<1$. The evolution of the asset quality $s$ during the investment and non-investment periods, and of the input $m$ can be determined with approximate formulas provided in Appendix V. These calculations show that both variables are bounded, and their upper values do not depend on the contract length $T$. The bounds are given by

$$
\begin{aligned}
& s(t)<\max \left(s_{0}, \frac{g_{0} \bar{n}}{\mu A m^{\alpha}(t)}\right) \text {, and } \\
& m(t)<\max \left(\left(\frac{\alpha A s_{0}}{c_{m}}\right)^{1 /(1-\alpha)}, \frac{\alpha g_{0} \bar{n}}{c_{m} \mu}\right) .
\end{aligned}
$$

The evolution of the stock of the asset over time is shown in Fig. 2. Our linear specification of the investment function $g(n)=g_{0} n$ leads to a kink of the trajectory of $s(t)$. We conjecture that a nonlinear formulation of the investment function would lead to a smoother change of the trajectory of $s(t)$, but would maintain its upward and downward sloping segments. 
Fig. 2 Evolution of the asset quality over time

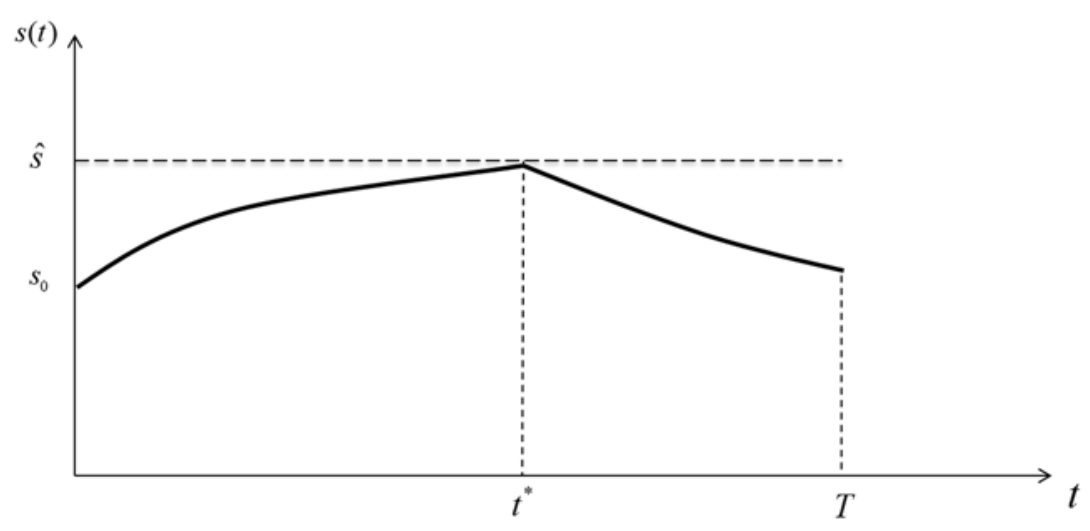

The approximate formulas (28) - (30) are critical for revealing the asymptotic behavior of the agent's problem when the contract duration is large. These results extend the previous literature by providing precise information about the length of the investing and noninvesting periods, beyond the commonly used two-period model. The asymptotic analysis of the following section relates the approximate dynamics of this section to the first-best solution of the agent's problem described in Theorem 1. Moreover, it also serves as an additional validation of the formulas presented in this section.

\subsection{The case of long-term contracts}

Let us assume that the contract duration is large, i.e., $T>>1$, and consider the instants $t \in[0, T]$ such that $t^{*}>>0$ and $T-t^{*}>>0$. It is important to note that, by (30), the distance $T-t^{*}$ of the switching time $t^{*}$ from the contract-end $T$ remains bounded and does not increase with $T$. Now let us assume that $T \rightarrow \infty$. Then, for $t \rightarrow \infty$ and $T-t \rightarrow \infty$, we obtain that ${ }^{8}$

$$
s(t) \rightarrow \frac{g_{0} \bar{n}}{\mu A m^{\alpha}(t)},
$$

and by the equation (33)

$$
m^{1-\alpha}(t) \rightarrow \frac{\alpha g_{0} \bar{n}}{c_{m} \mu}(1-\mu \lambda(t)),
$$

and, by the equation (28) that

\footnotetext{
${ }^{8}$ For a more detailed derivation, please read Appendix V, in particular, the equations (59) and (62).
} 
$\lambda(t) \rightarrow \frac{A m^{\alpha}(t)}{r+\mu A m^{\alpha}(t)}$.

Recalling formulas (14) - (17) for the efficient investment solution $(\hat{m}, \hat{n}, \hat{s}, \hat{\lambda})$, we observe that in the case of contracts that are long enough, the optimal trajectories approach the efficient investment solution

$n(t)=\hat{n}, \quad m(t) \approx \hat{m}, \quad s(t) \approx \hat{s}, \quad \lambda(t) \approx \hat{\lambda}$.

However, the trajectories deviate from these values at the beginning and end of the contract interval.

We provide an illustration of the qualitative dynamics of the optimal trajectories in two different cases: when the initial asset quality $S_{0}$ is smaller and when it is larger than the sustainable quality, $\hat{s}$. Let us consider two solutions denoted by $s^{1}(t)$ and $s^{2}(t)$, with the corresponding initial values for the asset, $s_{0}^{1}>\hat{s}$ and $s_{0}^{2}<\hat{s}$.

The trajectories of $s(t)$ and $\lambda(t)$ are depicted in Fig. 3. If the initial asset quality $s_{0}^{1}$ is larger than the sustainable quality $\hat{s}$, the asset quality as well as the shadow price decrease over time. The agent's investments until $t^{1^{*}}$ are not sufficient to compensate the high production intensity, so that the asset quality declines. If the initial asset quality $s_{0}$ is smaller than the sustainable quality $\hat{s}$, then the asset quality increases over time. In this case, the agent's investment is accompanied by modest production intensity, so that the asset quality increases. The mathematical justification of these trajectories is provided in Appendix VI. 
Fig. 3 Evolution of the asset quality and corresponding shadow price over time in long-term contacts

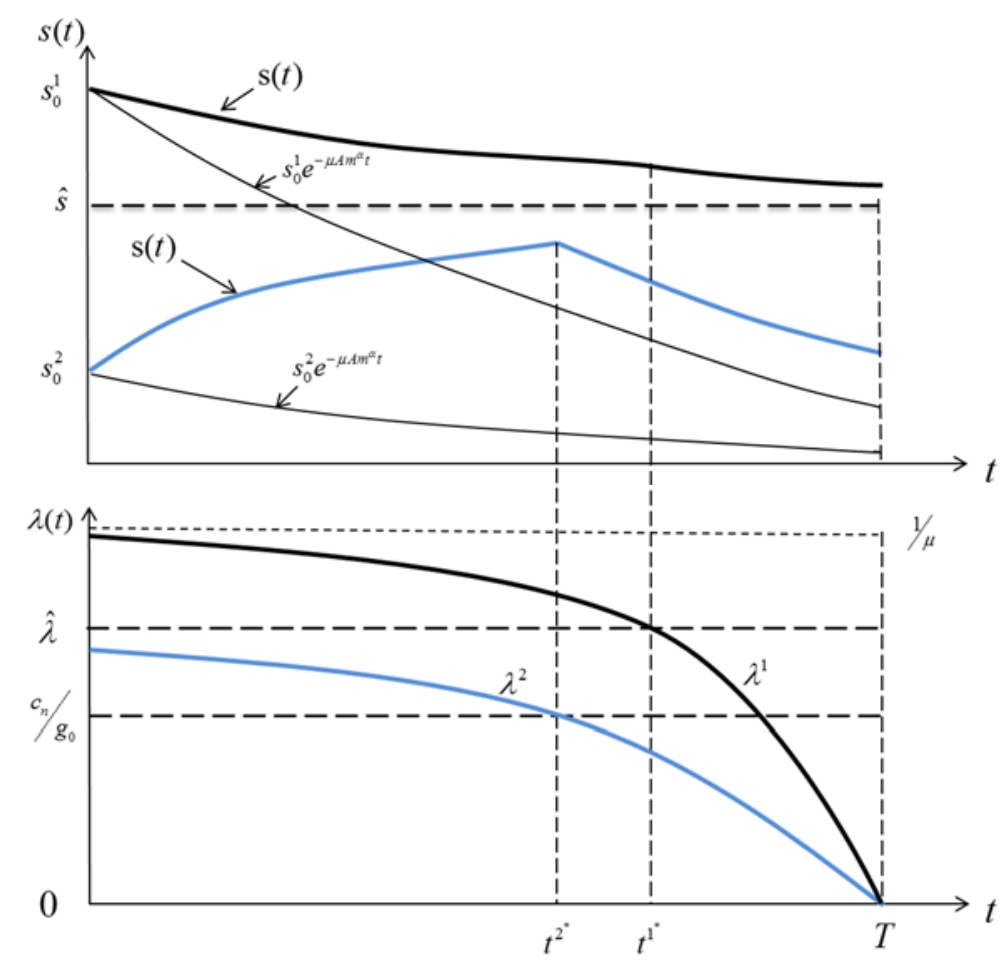

In addition to a new insight into optimal dynamics of the environmental system under study, one of the relevant practical outcomes of our theoretical analysis is that the optimal input $m(t)$ is close to its efficient investment value $\hat{m}$ for long-term contracts. In particular, it allows us to use $\hat{m}$ in (30) to obtain a practically applicable estimate for the switching time $t^{*}$ of the investment $n$ at $T>>1$ :

$t^{*} \approx T+\ln \left[1-\frac{c_{n}}{g_{0}}\left(\mu+\frac{r}{A \hat{m}^{\alpha}}\right)\right] \frac{1}{r+\mu A \hat{m}^{\alpha}}$.

The equation (37) reveals that a low investment $\operatorname{cost} c_{n}$, a large effect of the investment $g_{0}$ on the asset quality, a high productivity of the input $A m^{\alpha}$, and a low value of deterioration rate $\mu$ tend to moderate the hold-up problem. Further insights from the equation (37) are drawn in the sections that follow.

\section{Remedies for the hold-up problem}

In this section, we summarize the implications of our analytic results and provide meaningful and applicable recommendations for contract design and avoidance of the hold-up problem. 
Although these results are obtained for a special case of production, deterioration and investment functions, they allow the identification of the fundamental factors that determine the severity of the hold-up problem and indicate central arguments for overcoming it.

\section{Theorem 2 (on avoiding the hold-up problem and renegotiation)}

The hold-up problem and incentives for renegotiation do not arise if the principal offers the agent a new contract at the time $t^{*}<T$ and the stock has reached its steady-state value $\hat{s}$ before this point in time. The new contract starts at $t^{*}$ and lasts $T$. The length $T-t^{*}$ of the advance notice does not depend on the length of the contact $T$ if the stock reaches its steadystate value $\hat{s}$ while the contract is in place.

Proof: An agent will not change his investment behavior at the time $t^{*}$, if the contract is renewed at this point, because the time period $T-t^{*}$ towards the end of the current contract is completely covered (overlapped) by the time period $0-t^{*}$ of the new contract. Thus, overcoming the hold-up problem requires the principal giving an advance notice of the renewal of the contract length $T-t^{*}$. By (37), in the case of long contracts $(T \rightarrow \infty)$, the length of the advance notice can be estimated as

$T-t^{*} \approx \frac{1}{r+\mu A \hat{m}^{\alpha}} \ln \left[1-\frac{c_{n}}{g_{0}}\left(\mu+\frac{r}{A \hat{m}^{\alpha}}\right)\right]$.

The principal can calculate the advance notice period for a given $T$ or for a preferred renewal interval $t^{*}$ of the contract by adjusting the contract length $T$. The result is a sequence of identical overlapping contracts with the renewal frequency $t^{*}$ and advance notice time $T-t^{*}$. The approximate formula (38) also shows that any increase in $T$ is accompanied by a corresponding increase in $t^{*}$ in such a way that $T-t^{*}$ is independent of the choice of $T$ and $s(0)$. For Theorem 2 to hold, it is required that the stock achieves the steady state value $\hat{s}$ while the contract is in effect. In other words, it requires that the initial value of the stock does not influence the non-investing period, i.e. the values $T$ and $t^{*}$. Thus, Theorem 2 covers the cases where the initial stock is equal to $\hat{s}$ or where the sequence of contracts allows reaching $\hat{s}$ while the first contract is in place. If $\hat{s}$ cannot be reached during the first contract, then the length of sequential contracts is not identical and is discussed in Section 7. 
Finally, since the agents can fully recover the investments of all contracts, there are no incentives to renegotiate the sequence of contracts, i.e., the sequence of contracts is renegotiation-proof up to the final contract of the sequence.

The formula (38) is highly policy relevant, because it provides a valuable advice for overcoming the hold-up problem as described in Observation 3 and Theorem 2. The hold-up problem arises because of the lack of commitment on the part of the principal to compensate the agent for his investment. The principal cannot honor any commitment because the investments of the agent are not verifiable by a third party. Changes in the asset quality may result from the agent's investment or from external influences (for example, the weather, attitude of the personnel, or market variations). Hence, the principal cannot assess the investment behavior of the agent using only the evolution of the asset quality. For this reason, the asset quality, although ex post observable, is not contractible. The advance notice, however, is verifiable by both parties, and consequently the principal can commit to give an advance notice. The time dimension of the relationship may, therefore, form an integral part of a contract.

Observation 3 (the substitution of the efficient investment solution by a sequence of fixed-time contracts)

(i) If $T<\frac{-1}{r+\mu A \hat{m}^{\alpha}} \ln \left[1-\frac{c_{n}}{g_{0}}\left(\mu+\frac{r}{A \hat{m}^{\alpha}}\right)\right]$, then the long-run optimum cannot be achieved by a sequence of renewable contracts.

(ii) Otherwise, it is possible to achieve the long-run optimum by a sequence of contracts that are renewed at the time $t^{*}<T$.

Proof: The second term of the sum in (37) is negative. Therefore, if the length of the contract $T$ is relatively short, then the value of $t^{*}$ is less than or equal to zero in (37). Hence, it is optimal for the agent not to invest at all and, consequently, there would be no sequence of short-term contracts that approximate the optimal long-run contract. As soon as the value of $t^{*}$ is strictly positive, the agent starts investing and a sequence of short-term contracts of the length $T$ renewed at time $t^{*}$ can be employed to establish the long-run optimum.

As a result of Observation 3, the minimal contract length $\underline{T}$ that induces the agent's investment is defined by 
$\underline{T}=\frac{-1}{r+\mu A \hat{m}^{\alpha}} \ln \left[1-\frac{c_{n}}{g_{0}}\left(\mu+\frac{r}{A \hat{m}^{\alpha}}\right)\right]$.

Thus, the principal could induce the agent's investment with any contract duration larger than $\underline{T}$. However, the principal's function $V(T)$ of the costs and benefits of contract renewals limits the length of the offered contract duration. The offered contract time $T^{*}$ by the principal is defined in Observation 4.

\section{Observation 4 (the length of the offered contract)}

The principal's offered contract time $T^{*}$ is given by

$$
T^{*}=\left\{\begin{array}{cccc}
T^{\min }, R=\hat{R}_{\infty}, & \text { if } & T^{\min }>\underline{T}, & \hat{I}\left(T^{\min }\right)>0 \\
\underline{T}+\varepsilon, R=\hat{R}_{\infty}, & \text { if } & T^{\min } \leq \underline{T}, & \hat{I}(\underline{T}+\varepsilon)>0 \\
0, & \text { if } & T^{\min } \leq \underline{T}, & \hat{I}(\underline{T})<0
\end{array}\right\} .
$$

Proof: Provided that the aggregate income stream is positive, the principal offers the contract length $T^{\mathrm{min}}$, since it minimizes the costs and benefits of renewal and induces the agent's investment $T^{\mathrm{min}}>\underline{T}$. Likewise, to ensure a positive income stream, the principal has to offer a contract of a larger length $\underline{T}+\varepsilon, \varepsilon>0$, since it induces the agent's investment. If either $\hat{I}(\underline{T}+\varepsilon)$ or $\hat{I}\left(T^{\min }\right)$ are negative, then the principal prefers not to make an offer, since the costs and benefits of renewal are higher than the aggregate income stream. This case could happen if uncertainty and/or the minimum contract length are large.

Under different assumptions, Rey and Salanie $(1990,1996)$ obtain conclusions similar to part (i) of Observation 3 in the case of moral hazard (1990) and adverse selection (1996). However, our results cannot be compared directly, because they considered a case where neither the agent nor the principal invest. In our model, the principal and agent have identical information at the contracting date, but not as the contractual relationship unfolds. The principal may have information about the quality of the asset, but not about the agent's investment behavior. The findings of this paper emphasize the importance of a minimum length of short-term contracts, so that the long-run optimum can be achieved. If the contract duration is too short, then no investment will take place. In other words, if investments are 
important, only a sequence of "reasonably long short-term" contracts can serve as a substitute for the long-run optimum.

The seminal paper by MacLeod and Malcomson (1993) analyzes three different situations when market contracts are incomplete but can induce efficient investment. One of them is when both market partners realize relationship-specific investments. As such, there are incentives for renegotiation once an external shock has occurred. The authors find that efficiency can be achieved in this situation if the terms of a contract are conditioned on the status of an external variable, such that the parties have no reason for renegotiation. MacLeod and Malcomson argue that these contract terms induce efficiency for the one- and multiperiod cases. The article differentiates between investments in the form of a flow variable that creates value only within the contractual relationship (specific investment) and one that creates value independent of the relationship (general investment). This distinction is crucial to derive the contract terms necessary to induce efficient investment. However, if investment is not a flow but a stock variable, then this distinction will be diluted. Although the investment is still relationship-specific, part of it continues to exist even after the termination of the contract and becomes a non-relationship specific investment. Consequently, the contract terms defined are no longer sufficient to induce efficient investment. Additionally, although the article is based on multi-periods, the length of these periods is not discussed. This is why we introduce the dynamics of the investment, so that we can determine the lengths of the investment and the non-investment periods. Moreover, we explicitly introduce time controls as external variables that are easily verifiable.

Che and Sákovics (2004) postulate that dynamic investment after the signature of contracts can provide incentives for avoiding the hold-up problem, at least, asymptotically. Their model is based on "contribution games" and is difficult to compare with ours. Yet, our findings suggest that dynamic investment alone does not provide a solution to the hold-up problem and that modified contracts are necessary for overcoming it. Pitchford and Snyder (2004) show that dynamic investments may open a way to design contracts that can overcome the hold-up problem to a large extent. They propose that the non-investing party compensates the investing party for each installment of the investment while the contract is in force. The non-investing party's incentive resides in the threat of the investing party not to realize further investments. A given installment should not exceed a certain size, otherwise the noninvesting party's benefits from the investment would exceed the punishment given by the loss 
of future investment. As pointed out by the authors, efficiency requires that the sequence of investments is not finite and the size of the installments should gradually decrease over time. This asymptotic efficiency seems particularly adequate for staged procurement processes where specific investments are the central part of the contractual relationship. In contrast, our research focuses on contracting on time as an alternative to overcoming the hold-up problem. Guriev and Kvasov (2005) propose establishing the first-best outcome by incorporating advance notice within an open-end contract. This result is obtained for the case where investments are additively separable over time and the expected value of the arrival of the outside option is memoryless and constant over time. The authors show that a sequence of fixed time contracts and advance notice is only efficient at the time the contract is signed. Every moment thereafter, the contract is not efficient anymore, so that it needs to be renegotiated for each moment that passes. The model of Guriev and Kvasov (2005) leads to first order conditions that are stationary, which in turn implies the necessity of renegotiation. Most likely continuous renegotiations cannot be an efficient solution in terms of associated costs. For this reason, the authors extend their Proposition 1 (sequence of continuously renegotiated fixed time contracts) to the case of open-end contracts (Proposition 2). Guriev and Kvasov (2005) show that open-end contracts with advance notice are efficient. In this respect, our study extends the current literature by showing that a sequence of fixed time contracts (except for the last contract) that are renegotiation-proof up to time $t^{*}$ is already able to replicate the first-best outcome. Thus, the fixed time contracts are efficient over the entire time horizon of $T-t^{*}$ and there is no need to offer open-end contracts in order to achieve efficiency.

Observation 3 shows that the first-best outcome can only be achieved by taking into account the interrelations among the optimal contract duration, the minimal advance notice time, and the asset quality. The quality of the asset influences the optimal contract duration and minimum advance notice time. For instance, Brickley et al. (2006) analyzed the duration of franchise contract and found that it is positively related to the franchisee's physical and human capital investments. Similarly, Joskow (1987, 1990) and von Hirschhausen and Neumann (2008) observed that agents make longer commitment when asset-specific investments are important. Obviously, the required investments for all cases depend on the asset quality at the beginning of the contract. 


\section{Observation 5 (the length of non-investment period)}

In the case of sufficiently long contracts, the length of the non-investment period practically does not depend on the contract length. The non-investment period is shorter for higher asset productivity A.

Proof: The equation (38) shows that the difference $T-t^{*}$ asymptotically does not depend on $T$ when $T \rightarrow \infty$. Consequently, changes in the length of the contract lead to changes in the optimal switching time, but do not affect the length of the non-investment period. The equation (38) also shows that a higher productivity $A m^{\alpha}$ shortens the value $T-t^{*}$.

That is, the optimal switching time $t^{*}$ is closer to $T$ and the non-investment period is shorter for a lower unit $\operatorname{cost} c_{n}$, a lower asset deterioration rate $\mu$, or for a larger investment improvement effect $g_{0}$.

Our results have been obtained under the assumption that the investment function is linear in $n$. Yet the validity of this assumption may be questioned and one may wonder under what conditions this assumption is justified. The most straightforward argument is given for the case where investment costs are relatively small compared to the additional benefits obtained. Thus, agents have incentives to invest the maximum amount that is compatible, or it may even be required if the agents operate with fixed proportion technology with respect to $n$. Hence, agents tend to choose the upper limit of the domain of the investment variable. Our empirical illustration (see Section 8), where agents lease agricultural land, is a typical example of this situation. Organic fertilizer is relatively cheap so agents apply the maximal amount permitted. If the marginal benefits of investment are equal to their marginal costs in the interior of its domain, the assumption of linearity in $n$ does not reflect the agents' decision behavior well. In this case, the function $g(n)$ had to be specified as a nonlinear function. As long as this function is monotonously increasing in $n$, we would expect that a sequence of fixed-time contracts is still able to replicate the first-best outcome although investment behavior adjusts more gradually over time and is not characterized by bang-bang behavior. The gradual investment behavior is likely to affect the minimal contract length $\underline{T}$ which in turn affects the optimal contract length $T^{*}$ offered by the principal. Observation 4 determines the optimal contract length as a function of the minimal contract length $\underline{T}$ and the 
principal's minimum renewal costs or losses $T^{\mathrm{min}}$. If the gradual investment behavior requires a very long contract duration, it may be optimal for the principal not to offer any contract as reasoned in the proof of Observation 4. Although the consideration of nonlinearity in $n$ affects the minimal contract length, the structure for determining the optimal contract length (as stated in Observation 4) remains valid.

\section{Contract duration, switching time and non-investment period off the efficient investment path}

So far, we have assumed that the length $T$ of all sequential contracts is identical. However, the equations (23) - (26) show that trajectories of the state and control variables depend on the initial value $s_{0}$ of the asset quality $S$ and, thus, $s_{0}$ may also affect the choice of the optimal contract length. Strictly speaking, if the initial asset quality is not equal to $\hat{s}$, then a sequence of contracts with identical length cannot be optimal. The contract length of the sequence of contracts should be adjusted until the stock has reached the steady-state stock $\hat{s}$. Our model allows for a dynamic description of this process, because it considers the asset quality as a stock variable. The equation (27) describes the minimal contract length $T$ from which agents start investing up to time $0<t^{*}<T$. It shows that the minimum contract length is larger for smaller initial values $s_{0}$ of asset quality stock. So, if the initial stock $s_{0}$ is below the steady- state stock, then the contract length of the initial contract should be larger than the long-run optimal contract length $T^{*}$. The principal offers the agent a contract whose length depends on costs and benefits of the renewal. In the case when the initial contract does not allow achievement of $\hat{s}$, the principal offers a sequential contract shorter than the previous one but still longer than $T^{*}$. Analogously, the length of the initial contract should be shorter than the long-run length $T^{*}$ if the initial value of asset quality is above the steady-state $\hat{s}$. Our dynamic analysis in Section 5 demonstrates that, in both cases $s_{0}<\hat{s}$ and $s_{0}>\hat{s}$, the asset quality $s(t)$ approaches its steady-state value $\hat{s}$ starting from an initial value $s_{0}$. If the stock reaches $\hat{s}$, the length of the contract in the offered sequence of contracts is equal to $T^{*}$ as formulated in Observation 4. The principal's need to offer longer contracts may provoke $I(T)$ to become negative, in particular, if $T \gg T^{\mathrm{min}}$. In this case it is optimal for the principal 
not to offer any contract. Hence, if the initial asset quality is very distant from steady-state stock, the need to offer longer contracts may impede not offering any contract at all.

When the contract length $T$ for all contracts $j$ in (1) is identical, it is natural to raise the question whether a sustainable solution $\tilde{s}(t), t \in[0, T]$, exists such that the initial value of the asset quality equals its terminal value, i.e., $\tilde{s}_{0}=\tilde{s}(0)=\tilde{s}(T)$. Such solution is the same on all subsequent intervals and, correspondingly, guarantees a sustainable use of the asset. We refer to this type of solution as a periodic solution of the principal's problem. An analysis reveals that a periodic solution does not replicate the first-best outcome. However, it preserves the asset quality and leads to efficient investment, though it is not first-best. ${ }^{9}$

Following our game setup, the principal is the residual claimant of the variations of the net benefits over time. This result points at differences between findings related to the principalagent problem in some literature (Laffont and Martimort 2002). A standard result is that the agent is fully incentivized as a residual claimant, if the rent is a fixed amount and does not depend on the output or net benefits. This difference is explained by the fact that the existing literature does not consider a stock variable and the relationship between the actions taken by the agent and the resulting net benefits are normally assumed to be stochastic. Hence, one can find a variation of the net benefits at each moment in time that can be claimed by the agent, because he just needs to pay a fixed amount of rent for the asset. However, since our model considers the hold-up problem, but not a moral hazard, the stock variation over time is rather deterministic than stochastic, and the principal can adjust the rent over time in order to extract any additional benefit.

\section{Empirical illustration}

In this section, we apply the general model presented above to the important specific case of a lease contract for agricultural land. Correspondingly, we refer to the owner as a landlord and the agent as a farmer or tenant, as these terms are more common in agricultural problems. In particular, we focus on the production of corn as a function of nitrogen fertilizer - either in its mineral or organic form. The mineral form is denoted by $m$ and the organic form by $n$. The application of organic fertilizer does not only provide nitrogen but also augments the

\footnotetext{
${ }^{9}$ To keep the presentation short, the analysis of periodic solutions is not presented, but it can be obtained from the authors upon request.
} 
content of organic matter in the soil, which in turn, improves the texture, the structure, the field capacity (water retention), the ion-exchange capacity and the slow release of mineral nitrogen in the soil. All these factors increase corn production. While mineral nitrogen is readily available for uptake by the plant, nutrients from organic fertilizers are not immediately available for uptake. The organic matter needs to be decomposed by the soil organism to replenish the soil with mineral elements and humus. The complete decomposition of organic material may take several years. Although the release of mineral elements is slow, it adjusts the availability of plant nutrients to the nutrient requirements as the crop grows. If the lease contract is not long enough, farmers do not have sufficient incentives to apply organic fertilizer, resulting in a hold-up problem.

\subsection{Specifications of model parameters and functions}

The production function $Y(m, s)$ is estimated based on data provided by Goetz and Martínez (2013), where the information about the productivity enhancing effect of organic matter is incorporated. Jenny (1980) reports that, for many types of soils, a minimum of $2 \%$ of organic matter is required in order to obtain average crop yields. This data is used to calibrate the specification of the production function. The most common mineral fertilizer is ammonium sulfate, which costs $0.3 € / \mathrm{kg}$. Considering a nitrogen content of $21 \%$ of ammonium sulfate, the overall costs of mineral fertilizer including transport and application are given by 1.578 $€ /$ Kg N (Díez and Fernández Alcázar 2013). The application of organic fertilizer, mostly in the form of sludge or litter, is more costly due to its volume. Given a weight of $2.5 \mathrm{~kg} \mathrm{~N} / \mathrm{m}^{3}$ and application costs of $2.28 € / \mathrm{m}^{3}$, the overall costs are given by $0.91 € / \mathrm{Kg} \mathrm{N}$.

The content of organic matter varies greatly between the different types of soil (Gallardo 2016), and frequently does not even reach $0.8 \%$ in Spain. Therefore, a buildup of organic matter would lead to a significant increase in corn production. Moreover, the production of corn accelerates the decomposition of organic matter in the soil and the degradation of soil structure. Given an average corn production of 12 tons per year and an average annual decomposition of $3 \%$ of the organic matter in soil, we can estimate the relationship between crop yields and the extraction of organic matter through harvest. The estimate of this parameter is $\mu=0.00924$. The application of organic fertilizer builds up the content of organic matter in soil at a rate of 0.00075758 per $\mathrm{kg}$ of nitrogen. For the actual calculations, 
we take into account that the 1991 European Nitrates Directive 91/676 limits the overall applications of organic fertilizer to $170 \mathrm{~kg}$ of $\mathrm{N}$ per year.

The chosen units of variables and values of parameters are presented in Table 1. The revenue function $B$ is given by $B(m, s)=p A m^{\alpha} s$.

Table 1. Units and parameter values

\begin{tabular}{cl}
\hline$S$ & organic matter (\%) \\
$m$ & $\mathrm{~kg} \mathrm{~N}$ (ammonium sulfate) \\
$n$ & $\mathrm{~kg} \mathrm{~N}$ sludge or litter \\
$A$ & 2.888 \\
$Y(m, s)$ & $A m^{0,13} \mathrm{~S}(\mathrm{t} / \mathrm{ha})$ \\
$c_{n}$ & $0.91 € / \mathrm{kg} \mathrm{N}$ \\
$c_{m}$ & $1.578 € / \mathrm{kg} \mathrm{N}$ \\
$p$ & $168.6 € / \mathrm{t}$ \\
$g_{0}$ & $0.00075758(\% / \mathrm{kg} \mathrm{N})$ \\
$\mu$ & $0.00924(\% / \mathrm{t} / \mathrm{ha})$ \\
$r$ & 0.03 \\
\hline
\end{tabular}

\subsection{Numerical analysis}

We solve the problem (1) - (6) numerically, given a lease contract over 20 years and an initial content of organic soil matter of $0.8 \%$. Fig. 4 shows the optimal trajectories of $m(t), n(t)$ and $s(t)$, and reveals that the pattern of the optimal trajectory of organic fertilizer is bangbang, with only one switching point. Fig. 4 also shows that the optimal trajectory of mineral fertilizer is always positive, which is consistent with Observation 1 . From the $17^{\text {th }}$ year onwards, the application of organic fertilizer, i.e., the investment in soil quality, is abandoned causing the hold-up problem to arise. It lasts until the end of the contract i.e., the noninvestment period persists for three years. Accordingly, the content of organic matter in soil increases up to year 17 and decreases thereafter, as shown in Fig. 4. 
Fig. 4 Optimal evolution of nitrate application, organic matter and soil quality over time

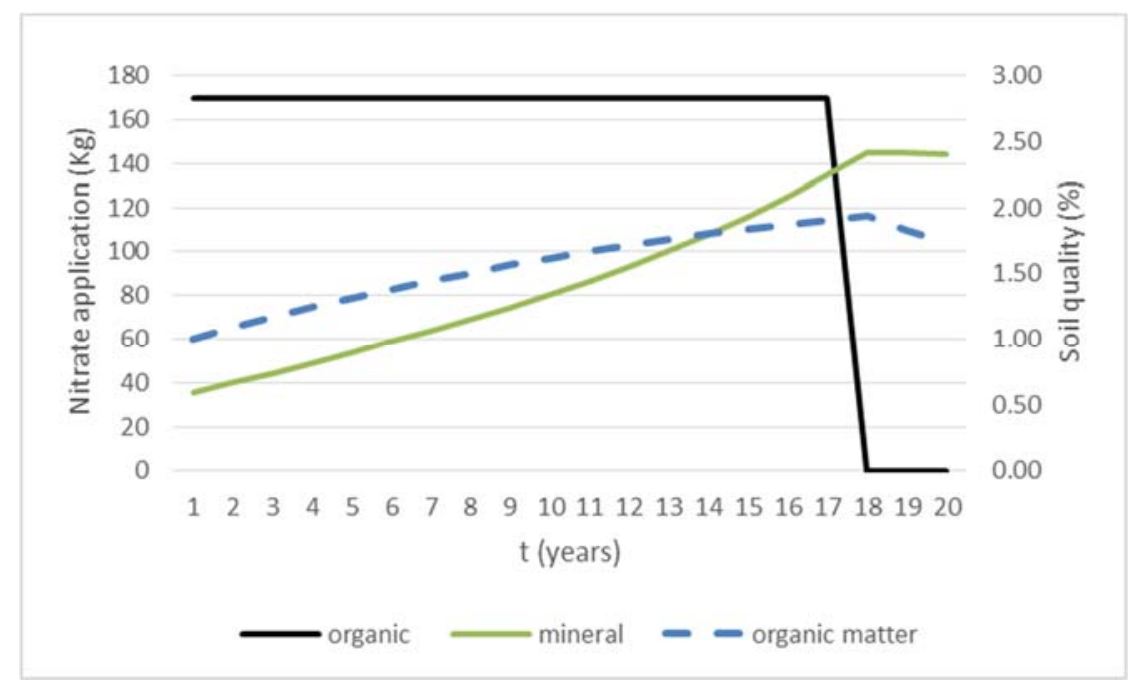

The calculations show that the choice of shorter or longer contract lengths $T$ has no influence on the length of the non-investment period $T-t^{*} .{ }^{10}$ The independence of $T-t^{*}$ on the contract length is in line with Observation 5. Specifically, if a contract lasts less than 3 years, then the farmer will not invest at all. In addition, the simulation results demonstrate that the efficient investment solution of Theorem 1, where the agent's contract is of infinite duration, exists and is given by $\hat{m}=77.87, \hat{n}=170, \hat{s}=2.66$.

Moreover, we analyze the sensitivity of the model with respect to changes in the parameter values. A decrease in the costs of organic fertilizer tends to moderate the hold-up problem as shown in the equation (37). For instance, the non-investment period decreases to 1 year when the cost parameter $C_{n}$ decreases by $50 \%$, while an increase of this unit cost by $50 \%$ raises the hold-up problem $\left(T-t^{*}\right)$ to 4 years. Changing the mineral fertilizer cost affects the length of the non-investment period in the same way as changing the cost of organic fertilizer, though the effect is less pronounced. A decrease in cost leads to a shorter non-investment period in both cases, because mineral and organic fertilizers act complementarily. When the costs of mineral fertilizer decrease, it is optimal to increase its use, which in turn, leads to an increase in the extraction. Also, increasing application of organic fertilizer compensates the reduction of the organic matter in the soil. Since organic fertilizer is bounded from above, the non-

${ }^{10}$ These results are not portrayed graphically in order to keep the presentation short. 
investment period begins at a later point in time. Variations of the parameters $g_{0}, A, p, \mu$ and $s_{0}$ also produce effects predicted above in Sections $4-6$.

Finally, the analysis shows that, when the initial level of organic matter in the soil equals the steady-state value of 2.66 , the efficient solution coincides with the sustainable trajectory, with a constant rent and a contract length of $T^{*}=13$, which is consistent with Observation 2 .

\subsection{Calibration and simulation of Guriev and Kvasov (2005) model}

Letting aside the necessity of continuous renegotiation, we calculate the optimal contract duration for the model proposed by Guriev and Kvasov (2005). We have calibrated their parameters based on the data of our numerical illustration (Table 1) and calculated the optimal time length of their fixed-time contract within their stationary setting. If we assume that the cooperative benefits accrue exclusively to the agent, we obtain that $T^{*}=8.744$ and, if the cooperative benefits are shared equally, we obtain $T^{*}=20.636$. Thus, the optimal time length depends largely on the share that each part receives. Apart from the share of cooperative benefits, the value of the arrival rate of outside option is fundamental in the determination of the optimal contract length. If the arrival rate is set to 0.5 (expected value of arrival 2 years) and the cooperative benefits accrue exclusively to the agent, the optimal contract length is reduced from 8.7 to 1.94 years.

The empirical illustration of our model (1) - (6) shows that the optimal contract length at the steady state is 13 years. Assuming that 13 years is equivalent to the expected arrival of the outside option, our simulation of the Guriev and Kvasov model (2005) gives the optimal value of $T^{*}=11.88$. Thus, under comparable situations, it appears that the optimal contract length of both models does not differ significantly. Yet, as soon as the values of the parameters change or the initial soil stock diverges from the steady-state stock, the optimal contract duration in our model deviates substantially from the optimal contract duration of their paper.

\section{Conclusions}

This study analyzes the agent's optimal investment behavior over time within a dynamic principal-agent framework. It assumes that the agent has rented a productive asset from the principal. Investing in the asset quality raises production and, at the same time, intensive 
production degrades the asset quality. The present study extends the previous literature, by accounting for the fact that investment and sharing of benefits are timewise intertwined and that past investments tend to influence cooperative benefits during the contract period. As a result, the study offers the design of contracts, where different elements of time are building elements and the dynamics of the productive asset is taken into account.

A mathematical analysis of the formulated dynamic principal-agent model with endogenous asset quality links its optimal dynamics to an efficient investment solution. It determines conditions under which the socially optimal and privately optimal solutions differ, with the difference resulting in the hold-up problem.

We find that time-based contracts where the length of the contract is the only time-related element may reduce the severity of the hold-up problem, but cannot eliminate it. However, the consideration of additional time-related contract elements allows designing contracts that lead to efficient investments. In particular, a sequence of overlapping fixed-time contracts encourages agents to invest efficiently and allows for the first-best outcome to be replicated. If the initial asset quality is sufficiently close to the optimal long-run asset quality, the sequence of overlapping contracts consists of identical contracts. If not, the contract length should be extended. However, the principal's need to offer longer contracts may result in her income becoming negative. In this case it is optimal for the principal not to offer any contract at all. In other words, the initial quality of the asset influences the principal's choice of contract length offered to the extreme that it may be optimal not to offer any contract at all. Since agents can recover their investments while the contract is in effect, they have no incentives to renegotiate it. The contracts are renegotiation-proof up to the last contract of the sequence of contracts. The overlapping itself is implemented as the renewal of a contract with sufficient advance notice. The study determines three fundamental elements of the sequence of overlapping short-term contracts, namely: the minimal length of the short-term contract, the length of the overlapping periods (advance notice period), and the frequency of renewals. Then, to attain the first-best solution, the principal needs to offer a sequence of overlapping fixed-time contracts that minimizes her search and transaction costs. 


\section{Acknowledgements}

This research has benefited from the financial support of the Generalitat de Catalunya XREPP (Xarxa de Referència d'R+D+I en Economia i Polítiques Públiques), the Ministerio de Economía, Industria y Competitividad (ECO2016-75927-R), and the Ministry of Education and Science of Kazakhstan (AP05131784).

\section{Appendix}

I Proof of Observation 1 (maximum value of the shadow price).

The analysis of the equation (11) for $r>0$ yields the following estimate:

$$
\lambda(t)<\int_{t}^{T} e^{-\int_{t}^{u} \mu A m^{\alpha}(\xi) d \xi} A m^{\alpha}(u) d u=\frac{1}{\mu}\left[1-e^{-\int_{t}^{T} \mu A m^{\alpha}(\xi) d \xi}\right]<\frac{1}{\mu} .
$$

The positivity of $m$ follows from (12). Next, we have $g_{0} \lambda(t)-c_{n}<g_{0} / \mu-c_{n}<0$ at $c_{n}>g_{0} / \mu$, and, therefore, $n(t)=0$ by $(8)$.

II Proof of Theorem 1 (on efficient investment regime).

If $c_{n}>g_{0} / \mu$, then $n=0$ by (15), and, therefore, all other unknowns are zero by (14), (16) (18). If $c_{n}<g_{0} / \mu$, then $\hat{n}=\bar{n}$ by (15). Substituting the last equality into (14), (16) - (18) and assuming $C=\frac{A \mu}{r}\left(\frac{g_{0} \bar{n} \alpha}{C_{m} \mu}\right)^{\alpha}>>1$, we determine a nontrivial positive solution to the system of three nonlinear equations (14), (16) - (18):

$$
\begin{aligned}
& \hat{\lambda} \approx \frac{1}{\mu}-\left(\frac{r}{\mu A}\right)^{1 /(\alpha+1)}\left(\frac{c_{m}}{g_{0} \bar{n} \alpha}\right)^{\alpha /(\alpha+1)}, \\
& \hat{m} \approx \frac{g_{0} \bar{n} \alpha}{c_{m} \mu}(1-\mu \hat{\lambda}), \\
& \hat{s} \approx \frac{g_{0} \bar{n}}{\mu A r \hat{\lambda}}(1-\mu \hat{\lambda}) .
\end{aligned}
$$

Indeed, substituting (16) into (14), we obtain that 


$$
\hat{m}=\frac{g_{0} \alpha \bar{n}}{c_{m} \mu}(1-\mu \hat{\lambda})
$$

Applying this result to (17), we obtain a single equation for $\hat{\lambda}$ given by

$\frac{A}{r}\left(\frac{g_{0} \bar{n} \alpha}{c_{m} \mu}\right)^{\alpha}(1-\mu \hat{\lambda})^{1+\alpha}=\hat{\lambda}$.

By (18), the unknown $\hat{\lambda}$ satisfies $\hat{\lambda}<1 / \mu$. Introducing the new variable $x, 0 \leq x=1-\mu \hat{\lambda}<1$, the equation (45) can be represented as

$$
\begin{aligned}
& C x^{\alpha+1}=1-x, \text { where } C=\frac{A}{\mu r}\left(\frac{g_{0} \bar{n} \alpha}{c_{m} \mu}\right)^{\alpha}, \text { or } \\
& C^{1 /(\alpha+1)} x=(1-x)^{1 /(\alpha+1)} .
\end{aligned}
$$

Using clear geometric reasoning, the equation (47) has a unique solution $0<x<1$ given by the unique point of intersection of the graphs of the functions $C^{1 /(\alpha+1)} x$ and $(1-x)^{1 /(\alpha+1)}$. Finally, due to the condition $C>>1$, the parameter $C$ is large, therefore, $x$ is small by (46): $x<<1$, so that the equation (47) can be approximated as

$C^{1 /(\alpha+1)} x=1-X /(\alpha+1)$

or $x \approx C^{-1 /(\alpha+1)}$, which is formula (41). The theorem is proven.

\section{Monotonicity of the dual variable}

In the general case, it is difficult to estimate the sign of the derivative

$\lambda^{\prime}(t)=-A m^{\alpha}(t)+\left(r+A m^{\alpha}(t)\right) \int_{t}^{T} A m^{\alpha}(u) e^{-\int^{-}\left(r+A m^{\alpha}(\xi)\right) d \xi} d u$.

As mentioned above, we assume that $r<<1$. Then, by (23) and (49),

$$
\lambda(t) \approx \frac{1}{\mu}\left[1-e^{-\int^{T}\left(r+A m^{\alpha}(\xi) d \xi\right.}\right], \quad \lambda^{\prime}(t) \approx-A m^{\alpha}(t) e^{-\int_{t}^{T} A m^{\alpha}(\xi) d \xi}<0,
$$

And, hence, $\lambda(t)$ decreases monotonically.

\section{Minimum contract duration}

Applying the mean value theorem to the integral in the left-hand side of the equation (50) results in the following approximate equation for the shadow price of the asset 
$\lambda(t) \approx \frac{1}{\mu}\left[1-e^{-\left(r+\mu A m^{\alpha}(\zeta(t))\right)(T-t)}\right]$

where $t<\zeta(t)<T$ and $\lambda(T)=0$. By (21), the optimal investment $n(t)$ is zero if $\lambda(t)<c_{n} / g_{0}$. Hence, the condition for no investment strategy $n(t)=0$ is

$$
1-e^{-\left(r+\mu A m^{\alpha}(\zeta(t))\right)(T-t)}<\mu \frac{C_{n}}{g_{0}} \Rightarrow e^{\left(r+\mu A m^{\alpha}(\zeta(t))\right)(T-t)}<\left(1-\mu \frac{C_{n}}{g_{0}}\right)^{-1} .
$$

The condition (52) holds for all $0<t<T$ if

$T<-\frac{\ln \left(1-\mu c_{n} / g_{0}\right)}{r+\mu A \max _{[0, T]} m^{\alpha}(t)}$.

Hence, when the condition (53) is valid, we obtain the following representation for the control and state variables of the agent's problem

$$
\begin{aligned}
& n(t)=0, \\
& \lambda(t) \approx 1-\int_{t}^{T} e^{-\int_{t}^{u}\left(r+\mu A m^{\alpha}(\xi)\right) d \xi} A m^{\alpha}(u) d u, \\
& m(t) \approx\left(\frac{A \alpha}{c_{m}} s(t)[1-\mu \lambda(t)]\right)^{-\int_{0}^{-j} \mu A m^{\alpha}(\xi) d \xi},
\end{aligned}
$$

By (54) and (55), s(t) $\leq s_{0}$ and $\lambda(t)>0$, and therefore by (56)

$$
m(t)<\left(\frac{A \alpha}{c_{m}} s_{0}\right)^{\frac{1}{1-\alpha}} .
$$

Using the upper estimate (57) in the equation (53), we obtain the following a priori condition for the small contact length $T$ (such that the agent does not invest at all) in the terms of given model parameters:

$T<-\frac{\ln \left(1-\mu c_{n} / g_{0}\right)}{r+\mu A\left(A \alpha s_{0} / c_{m}\right)^{\frac{\alpha}{1-\alpha}}}$ as stated in the main text.

\section{Approximate solution}

If we assume that $\mu A<<1$ (while $A$ is not necessarily small), the equations (26), (51) and (54) suggest that the functions $m(t), s(t)$ and $\lambda(t)$ are slowly changing with $\dot{s}(t), \dot{\lambda}(t), \dot{m}(t)<<1$. Therefore, we can assume that $m(\xi) \approx m(t)$ in the equations (26), (51) 
and (54). Under these assumptions, the equations (23) and (24) can be solved analytically to obtain approximate solutions for $\lambda(t)$ and $s(t)$.

Indeed, then the approximate solution of the equation (23) yields directly

$\lambda(t) \approx \frac{1}{\mu+r / A m^{\alpha}(t)}\left[1-e^{-\left(r+A m^{\alpha}(t)\right)(T-t)}\right]$.

Under the assumption $\mu A<<1$, the solution of the equation (24) leads to the following approximate expressions for the evolution of the asset quality $s(t)$ during the investment and non-investment periods:

$$
\begin{aligned}
& s(t) \approx s_{0} e^{-\mu A m^{\alpha}(t) t}+\frac{g_{0} \bar{n}}{\mu A m^{\alpha}(t)}\left[1-e^{\mu A m^{\alpha}(t) t}\right], \text { for } 0<t \leq t^{*} \\
& s(t) \approx s_{0} e^{-\mu A m^{\alpha}(t) t}+\frac{g_{0} \bar{n}}{\mu A m^{\alpha}(t)}\left[1-e^{-\mu A m^{\alpha}(t) t^{*}}\right] e^{-\mu A m^{\alpha}(t)\left(t-t^{*}\right)}, \text { for } t^{*} \leq t \leq T .
\end{aligned}
$$

By (59) and (60), the asset quality $s(t)$ remains bounded on any finite interval $[0, T]$ and satisfies the upper bound

$$
s(t)<\max \left(s_{0}, \frac{g_{0} \bar{n}}{\mu A m^{\alpha}(t)}\right),
$$

which does not depend on the length $T$ of the contract.

By (26) and (60), the trajectory of the input $m$ satisfies the nonlinear equation:

$$
m^{1-\alpha}(t)=\frac{\alpha A}{c_{m}}(1-\mu \lambda) s(t) \approx \frac{\alpha A}{c_{m}}\left[1-e^{-\left(r+\mu A m^{\alpha}(t)\right)(T-t)}\right]\left[s_{0} e^{-\mu A m^{\alpha}(t) t}+\frac{g_{0} \bar{n}}{\mu A m^{\alpha}(t)}\left[1-e^{\mu A m^{\alpha}(t) t}\right]\right]
$$

for $0<t<t^{*}$. Assuming that $m$ exists and using (31), we obtain the estimate for $m$

$$
m(t)<\max \left(\left(\frac{\alpha A s_{0}}{c_{m}}\right)^{1 /(1-\alpha)}, \frac{\alpha g_{0} \bar{n}}{c_{m} \mu}\right) .
$$

So, the input $m$ remains bounded and its upper bound is independent of the contract length $T$.

\section{Evolution of the asset quality and the shadow price}

It follows from (59) and (62) that $\frac{g_{0} \bar{n}}{\mu A m(0)^{\alpha}}<\frac{g_{0} \bar{n}}{\mu A \hat{m}^{\alpha}}$ where $s_{0}^{1}>\hat{s}$. Hence, the sum of two terms in (59) decreases with $t$. Moreover, as $T \rightarrow \infty$, we find that $t^{*} \rightarrow \infty$ by (30). Thus, $s\left(t^{*}\right)$ approaches $\hat{s}=\frac{g_{0} \bar{n}}{\mu A \hat{m}^{\alpha}}$ when the contract length $T$ increases and (59) can be rewritten as 
$s(t) \approx \frac{g_{0} \bar{n}}{\mu A m^{\alpha}(t)}+e^{-\mu A m^{\alpha}(t) t}\left[s_{0}-\frac{g_{0} \bar{n}}{\mu A m^{\alpha}(t)}\right]$.

In the case where $s_{0}^{2}<\hat{s}$, we observe that $\frac{g_{0} \bar{n}}{\mu A m(0)^{\alpha}}>\frac{g_{0} \bar{n}}{\mu A \hat{m}^{\alpha}}$, so that the sum of two terms in the equation (59) increases and $s\left(t^{*}\right)$ approaches $\hat{s}=\frac{g_{0} \bar{n}}{\mu A \hat{m}^{\alpha}}$ from below, while $0<t<t^{*}$.

Thus, in both cases, the corresponding trajectory of $s(t)$ approaches asymptotically $\hat{s}$ at $t \rightarrow t^{*}$, when $t^{*}$ is large. At $t^{*}<t<T$, the optimal asset quality $s(t)$ is governed by (60) and decreases exponentially in both initial situations. The optimal $n$ coincides with the efficient investment solution: $n(t)=\hat{n}$, while $0<t<t^{*}$.

\section{References}

Abdulai, A. and R. Goetz (2014). Time-related Characteristics of Tenancy Contracts and Investment in Soil Conservation Practices. Environmental and Resource Economics 59(1): 87109.

Aghion, P., M. Dewatripont and P. Rey (1994). "Renegotiation Design with Unverifiable Information." Econometrica 62(2): 257-282.

Aghion, P. and J. Tirole (1997). "Formal and Real Authority in Organizations." \ournal of Political Economy 105(1): 1-29.

Baker, G., R. Gibbons and K. J. Murphy (2002). "Relational Contracts and the Theory of the Firm." The Quarterly Journal of Economics 117(1): 39-84.

Bolton, P. and M. Dewatripont (2005). Contract Theory. Cambridge, MA, MIT Press.

Brickley, James A., S. Misra and R. L. Van Horn (2006). "Contract Duration: Evidence from Franchising." Journal of Law and Economics 49(1): 173-196.

Che, Y.-K. and J. Sákovics (2004). "A Dynamic Theory of Holdup." Econometrica 72(4): 10631103.

Colombo, F. and G. Merzoni (2006). "In praise of rigidity: The bright side of long-term contracts in repeated trust games." Journal of Economic Behavior \& Organization 59(3): 349-373.

Comino, S., A. Nicolò and P. Tedeschi (2010). "Termination Clauses in Partnerships." European Economic Review 54(5): 718-732.

Crocker, K. J. and S. E. Masten (1988). "Mitigating Contractual Hazards: Unilateral Options and Contract Length." The RAND Journal of Economics 19(3): 327-343.

Díez, C. and J. I. Fernández Alcázar (2013). "Abonos a la Carta." Cuaderno de Campo (52): 4 - 11. Evans, R. (2008). "Simple Efficient Contracts in Complex Environments." Econometrica 76(3): 459.

Felli, L. and K. Roberts (2015). "Does Competition Solve the Hold-up Problem?" Economica 83(329): 172-200.

Food and Agricultural Organization (2004). Land Reform, Land Settlement and Cooperatives. Rom, FAO.

Frascatore, M. R. (1997). "Staggered contracts and profitable entry deterrence: an application to professional sports." Journal of Economics 66(1): 71-86.

Gallardo, J. F., Ed. (2016). The Soils of Spain. New York, Springer. 
Goetz, R.-U. and Y. Martínez (2013). "Nonpoint source pollution and two-part instruments." Environmental Economics and Policy Studies 15(3): 237-258.

Gómez-Ibañez, J. A. (2003). Regulating Infrastructure Monopoly, Contracts, and Discretion. Cambridge, Massachusetts, Harvard University Press.

Goodhue, R., D. Heien, H. Lee and D. Sumner (2003). "Contracts and Quality in the California Winegrape Industry." Review of Industrial Organization 23(3-4): 267-282.

Grossman, S. J. and O. D. Hart (1986). "The Costs and Benefits of Ownership: A Theory of Vertical and Lateral Integration." Journal of Political Economy 94(4): 691-719.

Gul, F. (2001). "Unobservable Investment and the Hold-Up Problem." Econometrica 69(2): 343376.

Guriev, S. and D. Kvasov (2005). "Contracting on Time." American Economic Review 95(5): 1369-1385.

Harstad, B. (2012). "Climate Contracts: A Game of Emissions, Investments, Negotiations, and Renegotiations." The Review of Economic Studies 79(4): 1527-1557.

Hritonenko, N., Y. Yatsenko, R.-U. Goetz and A. Xabadia (2014). "Modeling of a landlord-tenant agricutural system in the environmental context." Natural Resource Modeling 27(4): 467-491.

Jacoby, H. G. and G. Mansuri (2008). "Land Tenancy and Non-Contractible Investment in Rural Pakistan." The Review of Economic Studies 75(3): 763-788.

Jenny, H. (1980). The Soil Resource, Origin and Behavior. New York, Springer

Joskow, P. L. (1987). "Contract Duration and Relationship-Specific Investments: Empirical Evidence from Coal Markets." The American Economic Review 77(1): 168-185.

Joskow, P. L. (1990). "The Performance of Long-Term Contracts: Further Evidence from Coal Markets." The RAND Journal of Economics 21(2): 251-274.

Laffont, J.-J. and D. Martimort (2002). The Theory of Incentives. Princeton Princeton University Press.

Lichtenberg, E. (2007). "Tenants, Landlords, and Soil Conservation." American Journal of Agricultural Economics 89(2): 294-307.

Long, N., R. Soubeyran and A. Soubeyran (2014). "Knowledge accumulation within an organization." International Economic Review 55: 1089-1128.

López-Bayón, S. and M. González-Díaz (2010). "Indefinite contract duration: Evidence from electronics subcontracting." International Review of Law and Economics 30(2): 145-159.

MacLeod, W. B. and J. M. Malcomson (1993). "Investments, Holdup, and the Form of Market Contracts." The American Economic Review 83(4): 811-837.

Pitchford, R. (1995). "Underinvestment and timber rights: An examination of the early Tasmanian and Victorian timber industires." Australian Journal of Agricultural Economics 38(3): 251-268.

Pitchford, R. and C. M. Snyder (2004). "A solution to the hold-up problem involving gradual investment." Journal of Economic Theory 114(1): 88-103.

Prives, G. (2013). "Evergreen clauses: Be aware of the pitfalls." Business Law \& Governance 6 (1): 1 - 3.

Rey, P. and B. Salanie (1990). "Long-term, Short-term and Renegotiation: On the Value of Commitment in Contracting." Econometrica 58(3): 597-619.

Rey, P. and B. Salanie (1996). "On the Value of Commitment with Asymmetric Information." Econometrica 64(6): 1395-1414.

Segal, I. and M. D. Whinston (2012). Property Rights. Handbook of Organizational Economics. R. Gibbons and J. Roberts. Princeton, Princeton University Press.

Townsend, R. E. and M. D. Young (2005). "Evergreen Leasing of Aquaculture Sites." Marine Resource Economics 20(2): 203-210.

von Hirschhausen, C. and A. Neumann (2008). "Long-Term Contracts and Asset Specificity Revisited: An Empirical Analysis of Producer-Importer Relations in the Natural Gas Industry." Review of Industrial Organization 32(2): 131-143. 
Voorhees, A. (2016). "The Enforceability of "Evergreen Clauses"." Insights Retrieved June 15th, 2018, from http://www.weltman.com/?t=40\&an=49799\&format=xml\&p=7735.

Wait, A. (2005). "Holdup and Innovation." Џournal of Economics (Zeitschrift fur Nationalokonomie) 85(3): 277-295.

Williamson, O. E. (1979). "Transaction-Cost Economics: The Governance of Contractual Relations." \ournal of Law and Economics 22(2): 233-261.

Worldbank (2011). PPP Insights. Public Private Partnership Projects in Infrastructure. Washington, Resource Center for Contracts, Laws and Regulation. 1.

Yoder, J., I. Hossain, F. Epplin and D. Doye (2008). "Contract duration and the division of labor in agricultural land leases." \ournal of Economic Behavior \& Organization 65(3): 714-733.

Zylbersztajn, D. and S. G. Lazzarini (2005). "On the survival of contracts: assessing the stability of technology licensing agreements in the Brazilian seed industry." Journal of Economic Behavior \& Organization 56(1): 103-120. 